\title{
SEASONAL ASSESSMENT OF SURFACE TEMPERATURE WITH NORMALIZED VEGETATION INDEX AND SURFACE ALBEDO OVER PAMPA BIOME
}

\author{
P. S. Käfer ${ }^{1,}{ }^{*}$, N. S. Rocha ${ }^{1}$, L. R. Diaz ${ }^{1}$, E. A. Kaiser ${ }^{1}$, S. T. L. Costa $^{1}$, G. Hallal ${ }^{1}$, G. Veeck ${ }^{2}$, D. Roberti ${ }^{2}$, S. B. A. Rolim ${ }^{1}$ \\ ${ }^{1}$ State Research Center for Remote Sensing and Meteorology, Universidade Federal do Rio Grande do Sul (UFRGS), Porto Alegre, \\ Brazil - pamelaskafer@gmail.com; najila.rocha@ufrgs.br; lucas.diaz@ufrgs.br; kaiser-eduardo@ hotmail.com; \\ savannahlemos95@gmail.com; gabrielhallal@gmail.com; silvia.rolim@ufrgs.br \\ ${ }^{2}$ Dept. of Physics, Universidade Federal de Santa Maria (UFSM), Santa Maria, Brazil - veeckgp@gmail.com; debora@ufsm.br
}

KEY WORDS: Grasslands, NDVI, LST retrieval, Thermal infrared remote sensing, Landsat data

\begin{abstract}
:
Land surface temperature (LST) governs many biophysical processes at the land-atmosphere interface and the relationship vegetation-LST has been the premise of many studies. This paper purposed to correlate LST with normalized difference vegetation index (NDVI) and surface albedo in the grasslands of Pampa biome during winter and summer seasons. Four Landsat 8 scenes with clear-sky conditions were acquired from the US Geological Survey website and NDVI and surface albedo were calculated. Afterwards, LST was obtained using Split-window (SW) algorithm. Results showed that LST in winter season exhibited less variations between pixels in comparison to summer, where the heterogeneity of the environment is significantly more detectable. LST retrieved from Landsat 8 data was consistent with the actual temperature measured in the field, with differences varying between 1-1.6 K. The LST-Vegetation relationship in the Pampa grasslands varies with the season so that caution must be taken in assuming a regular behaviour between LST and remote sensing vegetation variables, such as empirical relationships that are widely used in many scientific fields.
\end{abstract}

\section{INTRODUCTION}

Land surface temperature (LST) governs many biophysical processes at the land-atmosphere interface; therefore, it is a key parameter in environmental modelling from local to global scales (Hutengs, Vohland, 2016). Thermal infrared (TIR) remote sensing can be used to determine changes in the LST pattern, since corrections for the effects introduced by the atmosphere are performed (Coll et al. 2005).

The relationship vegetation-LST has been the premise of many studies, such as detecting land cover changes, evaluating vegetation dynamics, inferring evapotranspiration, among others (Goward, Hope, 1989; Julien, Sobrino, 2009; Mukherjee et al. 2014). Nevertheless, an irregular behavior between these two variables has been reported (Kaufmann et al. 2003; Liu et al. 2006).

Vegetation has been monitored traditionally by remote sensing through vegetation indices (IVs) (Käfer et al. 2018). Between the available IVs, the most widely applied is the normalized difference vegetation index (NDVI) (Rouse, 1973), which is a numerical indicator adopted to analyze remote sensing measurements and assess whether the target being observed contains live green vegetation or not (Kumar, Shekhar, 2015).

In contrast, surface albedo is a required variable for determining the magnitude of energy fluxes in the soil-plant-atmosphere continuum (Mattar et al. 2014), which is also used in many applications. For instance, albedo estimation accuracy affects the performance of evapotranspiration models (Sobrino et al. 2007; Vinukollu et al. 2011). Variations in surface albedo influence the spatial LST distribution by modifying the amount of solar radiation that is available to heat the land surface.

Pampa biome, in southern Brazil, is composed mostly by grassland vegetation interspersed with gallery forests. It is a complex biome with different vegetation types, among which the most representatives are fields dominated by grasses (Rubert et al. 2018). Although there are a considerable number of studies on the seasonal variations of Pampa biome vegetation along with climate variables, vegetation-LST relationship is not properly addressed on the literature. Most researches focused on air temperature data in conjunction with IVs or applied LST standard products (Fontana et al. 2018; Moreira et al. 2019), which present known limitations (Mukherjee et al. 2014; Simó et al. 2016).

The aim of this paper is to correlate LST with normalized difference vegetation index (NDVI) and surface albedo in the grasslands of Pampa biome. We intended to build a relationship between LST-NDVI and LST-albedo across two different seasons in order to contribute to the understanding of this peculiar system by capturing its complexity.

\section{METHODOLOGY}

\subsection{Study area}

Pampa biome is composed by natural grasslands that cover southern Brazil, Uruguay and central region of Argentina. Its typical ecosystem on the south of Brazil is a natural mosaic of Seasonal Forests from Atlantic Domain and grassland (Maragno et al. 2013). The Brazilian Pampa represents $63 \%$ of the Rio Grande do Sul state area, but $50 \%$ of the natural vegetation of Pampa biome was converted in pastures, crops and forestry currently (Oliveira-Filho et al. 2006).

Although the flora of the Pampa biome has more than 3000 species, it is dominated by about 450 species of forage grasses and more than 150 species of legumes. The development of this flora is due to the different effects associated with latitude, altitude, and soil fertility. Therefore, the biome presents unique characteristics in terms of vegetation/grass cover (Rubert et al. 2018). 
The area evaluated is located close to the Federal University of Santa Maria (coordinates: $29.725^{\circ} \mathrm{S} ; 53.760^{\circ} \mathrm{W}$ ), at the municipality of Santa Maria, Rio Grande do Sul State, Brazil (Figure 1). It is possible to see in the upper right and left corner a few spaces of human occupation.

The climate is subtropical humid, with annual precipitation of $1,708 \mathrm{~mm}$ and no dry season. Besides, it is characterized by seasonal variation of temperature, varying from zero or few negatives in the winter to $40^{\circ} \mathrm{C}$ in the summer, with the average annual temperature of $19.2^{\circ} \mathrm{C}$ (Maragno et al. 2013).

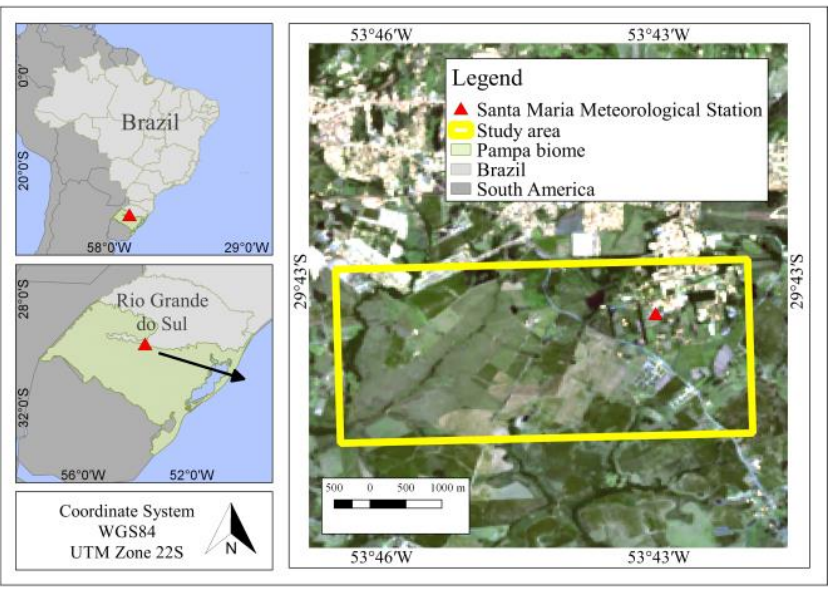

Figure 1. Location of the study site.

\subsection{Data acquisition}

Landsat 8 was launched on 11 February 2013 as a continuation of the Landsat Mission. The satellite carries two push-broom instruments, the Operational Land Imager (OLI) and the Thermal Infrared Sensor (TIRS). OLI has eight bands located from the visible to the short-wave infrared region, whereas TIRS has two channels in the TIR region of the electromagnetic spectrum (Duan et al. 2018).

We acquired four Landsat 8 scenes with clear-sky conditions from the US Geological Survey website <http:// www.earthexplorer.usgs.gov/>. TIRS bands were downloaded in Level-1 product in order to provide later thermal radiance and brightness temperature. Landsat Level-1 data are radiometric, geometric and terrain corrected and are available at a 100-meter spatial resolution.

To obtain the NDVI and surface albedo, Landsat 8 Level-2 surface reflectance products were also downloaded from the Landsat data collection. These products are generated at the Earth Resources Observation and Science (EROS) Center at a 30-meter spatial resolution. Specific information about the scenes used in this study is shown in Table 1.

\begin{tabular}{|ccccc|}
\hline Acquisition Date & Season & Path & Row & $\begin{array}{c}\text { Sun } \\
\text { Elevation }\end{array}$ \\
\hline 29 August 2019 & Winter & 223 & 80 & $43.50^{\circ}$ \\
18 February 2019 & Summer & 223 & 78 & $56.82^{\circ}$ \\
26 August 2018 & Winter & 223 & 78 & $42.51^{\circ}$ \\
15 February 2018 & Summer & 223 & 78 & $54.96^{\circ}$ \\
\hline
\end{tabular}

Table 1. Information of the Landsat 8 OLI/TIRS imagery.
The EROS Science Processing Architecture (ESPA) on-demand interface corrects satellite images for atmospheric effects to create Level-2 data products. The data are generated from the Land Surface Reflectance Code (LaSRC) that uses a unique radiative transfer model (Vermote et al., 2016).

\subsection{Determination of NDVI and surface albedo}

The NDVI considers that 'green' leaves absorb radiation at red wavelengths $(640-670 \mathrm{~nm})$ due to the presence of chlorophyll pigments whilst scattering radiance at very near infrared wavelengths $(700-1100 \mathrm{~nm})$ due to the leaves internal structure. On the other hand, a bare soil surface has higher reflectance at red wavelengths and lower reflectance at near-infrared wavelengths. The index scales between -1 and 1 and tends to have a more linear relationship with vegetation properties (Kumar, Shekhar, 2015).

Surface albedo is theoretically defined as the ratio between the up-welling and down-welling incident irradiance upon a surface (Mattar et al. 2014). Grasslands have higher albedo than dense vegetation. An increase in surface albedo leads to a reduction in net radiation, energy fluxes (sensible and latent), convective clouds and precipitation, leading to a drier atmosphere. In contrast, the slight decrease in the LST due to albedo increase is outweighed by a surface warming associated with a decrease in surface roughness, latent heat flux, rooting systems and evapotranspiration rate (Godinho et al. 2016). NDVI and surface albedo can be computed from the atmosphere reflectance in the OLI bands according to the equations exhibited in Table 2 .

\begin{tabular}{|c|c|c|}
\hline Description & Equation & Reference \\
\hline $\begin{array}{c}\text { Normalized } \\
\text { difference } \\
\text { vegetation index }\end{array}$ & $\begin{aligned} \mathrm{NDVI}= & (\rho 5-\rho 4) /(\rho 5 \\
& +\rho 4)\end{aligned}$ & $\begin{array}{l}\text { Rouse et } \\
\text { al. (1973) }\end{array}$ \\
\hline $\begin{array}{rr}\text { Surface } & \alpha= \\
\text { albedo } & +(\end{array}$ & $\begin{array}{l}55 \rho 2+0.130 \rho 4+0.373 \rho 5 \\
5 \rho 6+0.072 \rho 7-0.0018\end{array}$ & $\begin{array}{l}\text { Liang et } \\
\text { al. (2001) }\end{array}$ \\
\hline
\end{tabular}

Table 2. Summary of vegetation indexes applied in this study.

where $\quad \rho$ is the reflectance at each Landsat 8 OLI channel. $L$ depends on the type of soil. The common value applied is $\mathrm{L}=0.5$.

\subsection{Computation of LST and data processing}

For an atmosphere with clear conditions under local thermodynamic equilibrium, the thermal radiance observed at the top of the atmosphere (TOA) is expressed as the Radiative Transfer Equation (RTE) (Zheng et al. 2019) according to:

$$
L_{s e n, \lambda}=\left[\varepsilon_{\lambda} B_{\lambda}\left(T_{s}\right)+\left(1-\varepsilon_{\lambda}\right) L_{a t m, \lambda}^{\downarrow}\right] \tau_{\lambda}+L_{a t m, \lambda}^{\uparrow}
$$

where Lsensor is the at-sensor radiance in $\mathrm{Wm}^{-2} \mu \mathrm{m}^{-1} \mathrm{sr}^{-1}, \varepsilon$ is the land surface emissivity (LSE), $B \lambda(T s)$ is the Planck's law, $L \downarrow$ is the downwelling atmospheric radiance in $\mathrm{Wm}^{-2} \mu \mathrm{m}^{-1} \mathrm{sr}^{-1}$, $L \uparrow$ is the upwelling atmospheric radiance in $\mathrm{Wm}^{-2} \mu \mathrm{m}^{-1} \mathrm{sr}^{-1}$, and $\tau$ is the atmospheric transmittance.

In order to retrieve LST from remote sensing data Land surface Emissivity (LSE) must be known. An operational way to estimate LSE for Landsat data is to use the NDVI Threshold Method (NDVI ${ }^{\mathrm{THM}}$ ) (Sobrino et al. 2008), which estimates the emissivity values from the NDVI considering three different cases: 


$$
L S E\left\{\begin{array}{cl}
\varepsilon_{s \lambda} & N D V I<N D V I_{s} \\
\varepsilon_{V \lambda} P_{V}+\varepsilon_{s}\left(1-P_{V}\right)+d \varepsilon \lambda & N D V I_{s}<N D V I \\
\varepsilon_{V \lambda}+d \varepsilon \lambda & <N D V I_{V} \\
& N D V I>N D V I_{V}
\end{array}\right.
$$

where $P v$ is the vegetation proportion (Carlson, Ripley, 1997) calculated as follows:

$$
P_{V}=\left(\frac{N D V I-N D V I_{s}}{N D V I_{V}-N D V I_{s}}\right)^{2}
$$

where $\mathrm{NDVI}_{\mathrm{v}}=0.5$ and $\mathrm{NDVI}_{\mathrm{s}}=0.2$. The term $d \varepsilon$ includes the effect of the geometrical distribution of the natural surfaces and the internal reflections $(d \varepsilon=0$ for flat surfaces $)$. For heterogeneous surfaces, it can reach a value of $2 \%$ ( $\mathrm{Li}$ et al. 2013). $F$ is a shape factor whose mean value, assuming different geometrical distributions, is 0.55 .

$$
d \varepsilon=\left(1-\varepsilon_{S}\right)\left(1-P_{V}\right) F \varepsilon_{V}
$$

TIR data in satellite imagery sensors are stored in DNs so that they need to be converted to spectral radiance. Afterwards, radiance is converted to brightness temperature as:

$$
T_{\text {sen }}=\frac{K_{2}}{\ln \left(\frac{K_{1}}{L_{\text {sen }}}+1\right)}
$$

where Tsen is the satellite brightness temperature in Kelvin, $K I$ and $K 2$ are the band-specific conversion constant taken from the metadata file $(K 1=774.8853$ and $K 2=1321.0789$ for the Landsat 8 band $10 ; K 1=480.8883$ and $K 2=1201.1442$ for the band 11 ).

In this paper, the widely used Split-Window (SW) algorithm is applied. The basis of the technique is that the radiance attenuation for atmospheric absorption is proportional to the radiance difference of simultaneous measurements at two different wavelengths (Jiménez-Muñoz et al. 2014). Therefore, the LST is retrieved according to:

$$
\begin{aligned}
L S T=T i_{\text {sen }}+ & 1.378\left(T i_{\text {sen }}-T j_{\text {sen }}\right)+0.183\left(T i_{\text {sen }}-T j_{\text {sen }}\right)^{2}-0.268 \\
& +(54.3-2.238 w)(1-\varepsilon)+(-129.2+16.4 w) \Delta \varepsilon
\end{aligned}
$$

where $T i_{\text {sen }}$ and $T j_{\text {sen }}$ are the at-sensor brightness temperatures at the bands $\mathrm{I}$ and $\mathrm{j}$ (10 and 11) in Kelvins, $\varepsilon$ is the mean emissivity, $\varepsilon=0.5(\varepsilon i+\varepsilon j), \Delta \varepsilon$ is the emissivity difference, $\Delta \varepsilon$ $=(\varepsilon \mathrm{i}-\varepsilon \mathrm{j}), w$ is the total atmospheric water vapor content (in $\mathrm{g} \cdot \mathrm{cm}^{-2}$ ) retrieved according to Wang et al. (2015) method.

The input data required to obtain $w$ were taken from a nearby atmospheric observation station of the Brazilian National Institute of Meteorology (INMET) (Figure 1). Image processing was automated through the development of algorithms in MATLAB environment and Envi 5.3.

\section{RESULTS AND DISCUSSION}

\subsection{Spatial distribution of LST, NDVI and surface albedo}

The Table 3 shows the descriptive statistics of LST, NDVI and surface albedo for winter and summer. The mean of the two scenes for each season was considered. Moreover, the distribution of the three variables were classified into appropriate ranges (Figure 2) and colour-coded to create a distribution map of its pattern over the study site.
LST mean was around $293.5 \mathrm{~K}\left(20.4^{\circ} \mathrm{C}\right)$ and $299.2\left(26^{\circ} \mathrm{C}\right)$ in winter and summer, respectively. LST in winter season exhibited less variations between pixels in comparison to summer. Besides, in the winter all the variables produced the least value of standard deviation.

Figure $2 b$ shows more evident LST spatial variations, which are certainly related to the land use heterogeneity, more significantly detectable in summer season. Guha et al. (2019) mentioned that this type of LST variation is associated to the change in vegetation abundance and soil moisture content.

The spaces of open field with grasslands demonstrated lower temperatures, while the places with some kind of human occupation (upper right and left corner) presented higher temperatures. It is mainly because the calorific capacity of the urban materials (i. e. without vegetation cover) is high due to its constitution which has the non-evapotranspiration dry nature, causing the pad surface thermal conductivity to be big (Kumar, Shekhar, 2015).

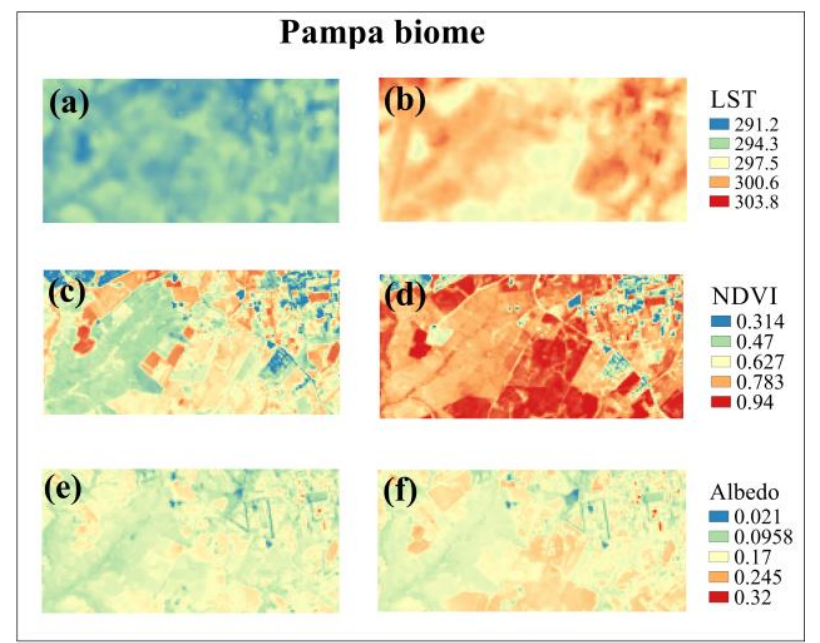

Figure 2. Spatial distribution Map of winter and summer seasons, respectively. (a) and (b) refers to LST; (c) and (d) to NDVI; (e) and (f) to Surface albedo.

The highest NDVI values were found in summer season. In contrast, the winter season had the lowest values (Figures 2c and d). Fontana et al. (2018) commented that this is a typical behaviour of the predominant subtropical climate in the region of Pampa biome. The authors also pointed out that winter is the critical season for cattle ranching, since the lower biomass accumulation and consequently lower NDVI values are conditioned by solar radiation and air temperature decrease.

The mean of NDVI was 0.77 and 0.59 in summer and winter, respectively, which are in agreement with predominantly vegetated areas (Table 3). According to Querino et al. (2016) NDVI is one of the most important biophysical parameters to characterize the canopy. Its spatial and temporal distributions are often used in global circulation models to provide information about energy flows and water. Thus, changes on the biophysical indices imply a deep change of several parameters such as photosynthesis, energy balance, evapotranspiration, net primary productivity, among others. 
Surface broadband albedo is essential to obtain reliable estimations related to land surface fluxes. Additionally, accurate surface albedo information is very important for weather forecasting, climate projection and ecosystem modelling (Zoran et al. 2013; Mattar et al. 2014). According to Bonan (2008) the higher is the vegetation cover, lower is the average surface albedo. In other words, tree canopies have lower albedo than grasslands; and much lower than bare soils. The results found in this work are in accordance, once higher albedos are seen in bare soil or urban land covers.

Similar to NDVI response, surface albedo produced lower values in winter season compared to summer, which is related to the high response of surface albedo changes to climate variations (Zoran et al. 2013), as a consequence of the lower energy availability in this season. Therefore, changes in climatic conditions strongly affect the phenological patterns and biomass production of Pampa biome natural grasslands, which are reflected on surface albedo.

\begin{tabular}{|ccccc|}
\hline Season & Min & Max & Mean & Std deviation \\
\hline \multirow{5}{*}{ Winter } & 291.16 & 295.59 & 293.51 & 0.64 \\
Summer & 296.54 & 303.77 & 299.18 & 1.29 \\
& & NDVI & & \\
Winter & -0.39 & 0.89 & 0.59 & 0.12 \\
Summer & -0.34 & 0.94 & 0.77 & 0.13 \\
& & Albedo & & \\
Winter & 0.021 & 0.31 & 0.14 & 0.025 \\
Summer & 0.024 & 0.32 & 0.17 & 0.027 \\
\hline
\end{tabular}

Table 3. Descriptive statistics of LST, NDVI and surface albedo.

\subsection{Validation of derived LST}

LST was measured in the field using a Campbell Sci/SI-111 sensor commercialized by Apogee Instruments, Inc., Roseville, CA, USA. SI-111 measures thermal-infrared radiance in the $8.0-14.0 \mu \mathrm{m}$ range and obtains brightness temperatures with an absolute accuracy of $\pm 0.2 \mathrm{~K}$ (Tang et al. 2015). The sensor is installed in an experimental site located within the study area (coordinates: 29 $43^{\prime} 27.5^{\prime \prime} \mathrm{S}$; 5345'36' W) about $30 \mathrm{~cm}$ above the ground, positioned so that it has a field of view of $22^{\circ}$.

As no in situ measurements were available for 2019, we only validated the data from 2018 scenes. Table 4 shows the results obtained from the image average (LST retrieved mean), the value of the pixel where the sensor is located (LST retrieved pixel) and in situ.

TIR data forms basis for monitoring evapotranspiration, water stress, estimation of surface energy flux, regional energy balance, drought, soil moisture, analysis of yearly land cover dynamics, among others (Mukherjee et al. 2018). Therefore, accuracy of LST measurements is required.

\begin{tabular}{|cccccc|}
\hline Date & $\begin{array}{c}\text { LST } \\
\text { Retrieved } \\
(\text { Mean })\end{array}$ & $\begin{array}{c}\text { LST } \\
\text { Retrieved } \\
(\text { Pixel })\end{array}$ & $\begin{array}{c}\text { LST } \text { in } \\
\text { situ }\end{array}$ & $\begin{array}{c}\text { LST } \\
\text { difference } \\
\text { (Mean })\end{array}$ & $\begin{array}{c}\text { LST } \\
\text { difference } \\
(\text { Pixel })\end{array}$ \\
\hline $\begin{array}{c}29 \text { August } \\
2019\end{array}$ & 298.96 & - & - & - & - \\
18 February & 296.38 & - & - & - & - \\
$\quad \begin{array}{c}2019 \\
26 \text { August } \\
2018\end{array}$ & 288.07 & 288.55 & 289.57 & -1.50 & -1.02 \\
$\begin{array}{c}\text { 15 February } \\
\text { 2018 }\end{array}$ & 301.99 & 299.40 & 301.04 & 0.95 & -1.64 \\
\hline
\end{tabular}

Table 4. Validation of LST retrieved from Landsat 8 data with in situ measurements in Kelvin.

Landsat 8 TIRS data is able to yield an accuracy of $1.5 \mathrm{~K}$ when SW technique is applied (Jiménez-Muñoz et al. 2014). Our finds are in agreement with the algorithm accuracy because direct validation in situ resulted in differences varying between 1-1.6 $\mathrm{K}$ in relation to the satellite measurements (Table 4). Although a characteristic LST pattern could be observed, the area analysed present enough homogeneity. Therefore, mean values of all LST pixels can be assumed.

\subsection{Relationship of LST with NDVI and surface albedo}

Figures 3 and 4 reveal the correlation between NDVI-LST and albedo-LST for winter and summer, respectively. The scatter plots of the two seasons demonstrated negative NDVI-LST relationship, mainly because NDVI represents the amount of biomass on the imagery and the low temperature is related to the high NDVI values (Querino et al. 2016). Similar results were found by Nimani (1993) and Deng et al (2018), in which the authors commented that the LST and NDVI of forest land, grassland and cultivated land are meant to have this behaviour, differently from urban environments (Guha et al. 2019).
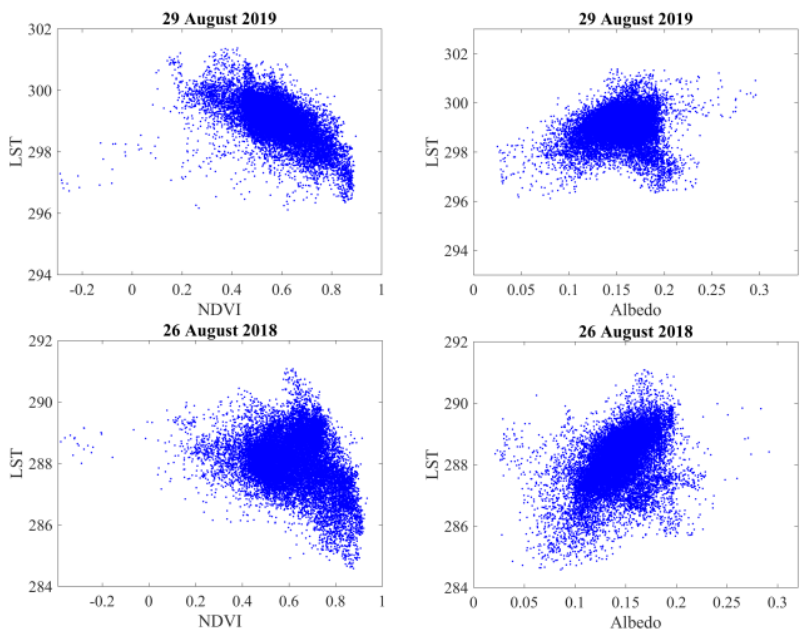

Figure 3. Scatter plot of the LST-NDVI and LST-Albedo relationships for the two winter images evaluated.

Winter season showed a weaker correlation relative to summer (Figure 3), when a higher amount of healthy green vegetation is reflected on NDVI values. Summer produced a correlation coefficient of -0.91 , whereas winter exhibited -0.85 (Table 5). In this context, Gallo and Owen (1999) and Marzbana et al. (2018) found that the strength of correlations between the variables depends on the season. According to the authors, while summer provides the strongest predictive capacity, the weakest is observed during winter season. 

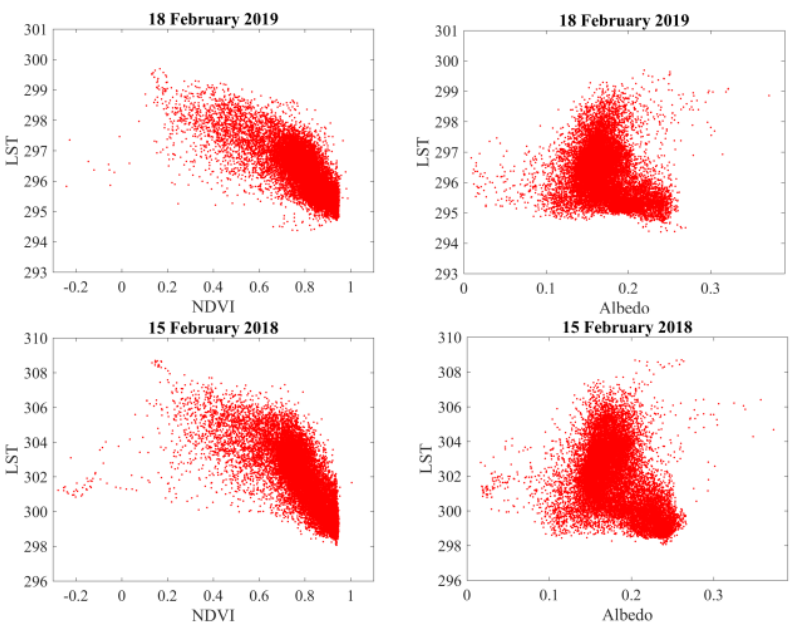

Figure 4. Scatter plot of the LST-NDVI and LST-Albedo relationships for the two summer images evaluated.

Figures 3 and 4 also show the relationship between surface albedo and LST. In fact, LST increases with decreasing albedo in summer season, which characterizes an inverse relationship with albedo. In the summer, correlation coefficient between albedo and LST was -0.33 . Winter season exhibited an opposite behaviour, with a mean correlation of 0.37 .

\begin{tabular}{|lcc|}
\hline Relationship & Winter (Mean) & Summer (Mean) \\
\hline LST-NDVI & -0.85 & -0.91 \\
LST-Albedo & 0.37 & -0.33 \\
\hline
\end{tabular}

Table 5. Correlation coefficients for LST-NDVI, LST-Albedo relationships.

Analysing the images separately (Figures 3 and 4) it is possible to note that the dates of 29 August 2018 (winter), 18 February 2018 and 15 February 2019 (summer) produced a trapezoid behaviour of albedo-LST. This relation is widely used by models that calculate evapotranspiration and the latent heat flux from remote sensing data. Yang and Wang (2011) assessed three simple models for estimating the evaporative fraction over the USA. All the models used only the scatter plot of NDVI or surface albedo with LST. The authors reported that the shapes of NDVI scatter plots are more clearly delineated than those of the albedo related to the LST difference.

\section{CONCLUSIONS}

Several studies have provided important information on LST and its relationship with driving environmental factors. The LST obtained by thermal remote sensing in conjunction with vegetation indices statistics allows researchers to comprehend the extent of the LST-Vegetation relationship and its efficacy. This study investigated the relations between LST-NDVI and surface albedo-LST in the natural grasslands of Pampa biome.

The LST retrieved from Landsat 8 data was consistent with the actual temperature measured in the field. The LST-Vegetation relationship in the Pampa biome grasslands varies with the season so that caution must be taken in assuming a regular behaviour between LST and remote sensing vegetation variables, such as empirical relationships that are widely used in many scientific fields.

\section{ACKNOWLEDGEMENTS}

The Landsat 8 OLI/TIRS product are a courtesy of the US Geological Survey Earth Resources Observation and Science Center. This study was financed in part by the Coordenação de Aperfeiçoamento de Pessoal de Nível Superior - Brazil (CAPES), finance code 001, the "Conselho Nacional de Desenvolvimento Científico e Tecnológico" (CNPq), Brazil.

\section{REFERENCES}

Bonan, G. 2008. Ecological climatology: Concepts and applications (2nd ed.). Cam-bridge: Cambridge University Press, $550 \mathrm{p}$.

Carlson, T. N. and Ripley, D. A. 1997. On the relation between NDVI, fractional vegetation cover, and leaf area index. Remote Sensing of Environment. 62(3), 241-252.

Coll, C., Caselles, V., Galve, J., Valor, E., Niclos, R., Sanchez, J., \& Rivas, R. 2005. Ground measurements for the validation of land surface temperatures derived from AATSR and MODIS data. Remote Sensing of Environment, 97(3), 288-300.

Deng, Y., Wang, S., Bai, X., Tian, Y., Wu, L., Xiao, J., Chen, F., Qian, Q. 2018. Relationship among land surface temperature and LUCC, NDVI in typical karst area. Scientific Reports, 8(641).

Duan, S-B., Li, Z-L., Wang, C., Zhang, S., Tang, B-H., Leng, P., Gao, M-F. 2018. Land surface temperature retrieval from Landsat 8 single-channel thermal infrared data in combination with NCEP reanalysis data and ASTER GED product. International Journal of Remote Sensing. 40(5-6), 1763-1778.

Fontana, D. C. Junges, A. H., Bremm, C., Schaparini, L. P., Mengue, V. P., Wagner, A. P. L., Carvalho, P. 2018. NDVI and meteorological data as indicators of the Pampa biome natural grasslands growth. Bragantia, 77(2), 404-414.

Gallo, K. P., T. W. Owen. 1999. Satellite-Based Adjustments for the Urban Heat Island Temperature Bias. Journal of Applied Meteorology, 38, 806-813.

Godinho, S., Gil, A., Guiomar, N., Costa, M. J., Neves, N. 2016. Assessing the role of Mediterranean evergreen oaks canopy cover in land surface albedo and temperature using a remote sensing-based approach. Applied Geography, 74, 84-94.

Goward, S. N., and A. S. Hope. 1989. Evapotranspiration from Combined Reflected Solar and Emitted Terrestrial Radiation: Preliminary FIFE Results from AVHRR Data. Advances in Space Research, 9(7): 239-249.

Guha, S., Govil, H., Diwan, P. 2019. Analytical study of seasonal variability in land surface temperature with normalized difference vegetation index, normalized difference water index, normalized difference built-up index, and normalized multiband drought index. Journal of Applied Remote Sensing, 13(2), 1-16.

Hutengs, C., Vohland, M. 2016. Downscaling land surface temperatures at regional scales with random forest regression. Remote Sensing of Environment, 178, 127-141.

Jiménez-Muñoz, J.C., Sobrino, J.A., Skokovic, D., Mattar, C., Cristobal, J. 2014. Land surface temperature retrieval methods from Landsat-8 thermal infrared sensor data. IEEE Geoscience Remote Sensing Letters. 11, 1840-1843. 
Julien, Y., and J. A. Sobrino. 2009. The Yearly Land Cover Dynamics (YLCD) Method: An Analysis of Global Vegetation from NDVI and LST Parameters. Remote Sensing of Environment, 113(2), 329-334.

Käfer, P. S., Rex, F. E., Breunig, F. M., Balbinot, R. 2018. Modeling Pinus Elliottii Growth with Multitemporal Landsat Data: A Study Case in Southern Brazil. Boletim de Ciências Geodésicas, 24(3), 286-299.

Kaufmann, R. K. L., Zhou, R. B. Myneni, C. J., Tucker, D., Slayback, N. V. Shabanov, and J. Pinzon. 2003. The Effect of Vegetation on Surface Temperature: A Statistical Analysis of NDVI and Climate Data. Geophysical Research Letters, 30(22) 3-6.

Kumar, D., Shekhar, S. 2015. Statistical analysis of land surface temperature-vegetation indexes relationship through thermal remote sensing. Ecotoxicology and Environmental Safety, 121, $39-44$.

Li, Z. L., Wu, H., Wang, N., Qiu, S., Sobrino, J. A., Wan, Z., Tang, B. H., Yan, G. 2013. Land surface emissivity retrieval from satellite data. International Journal of Remote Sensing, 34, 3084-3127.

Liang, S. 2001. Narrowband to broadband conversions of land surface albedo: I. Formulae. Remote Sensing of Environment, 76, 213-238.

Liu, Z., M. Notaro, J. Kutzbach, and N. Liu. 2006. Assessing Global Vegetation Climate Feedbacks from Observations. Journal of Climate, 19(5), 787-814.

Maragno, F. P., Santos, T. G., Cechin, S. Z. 2013. The role of phytophysiognomies and seasonality on the structure of grounddwelling anuran (Amphibia) in the Pampa biome, southern Brazil. Anais da Academia Brasileira de Ciências, 85(3), 11051116.

Marzban, F., Sodoudi, S., Preusker, R. 2018. The influence of land-cover type on the relationship between NDVI-LST and LST-Tair. International Journal of Remote Sensing, 39(5), 1377-1398.

Mattar, C., Franch, B., Sobrino, J. A., Corbari, C., JiménezMuñoz, J. C., Olivera-Guerra, L., Mancini, M. 2014. Impacts of the broadband albedo on actual evapotranspiration estimated by S-SEBI model over an agricultural area. Remote Sensing of Environment, 147, 23-42.

Moreira, A., Bremm, C., Fontana, D. C. Kuplich, T. M. 2019. Seasonal dynamics of vegetation indices as a criterion for grouping grassland typologies. Scientia Agricola, 76(1), 24-32.

Mukherjee, S., Joshi, P. K., \& Garg, R. D. 2014. A comparison of different regression models for downscaling Landsat and MODIS land surface temperature images over heterogeneous landscape. Advances in Space Research, 54(4), 655-669.

Nemani, R, Pierce, L, Running, S \& Goward, S 1993. Developing satellite-derived estimates of surface moisture status. Journal of Applied Meteorology, 32, 548-557.

Oliveira-Filho A. T., Jarenkow J. A. Rodal M. J. N. 2006. Floristic relationships of seasonally dry forests of Eastern South
America based on tree species distribution patterns. In: Pennington Rt et al. (Eds), neotropical savannas and dry forests: plant diversity, biogeography and conservation. Boca Raton: CRC Press, 151-184.

Rouse, J. W., Haas, R. H., Schell, J. A., Deering, D. W. 1973. Monitoring Vegetation Systems in the Great Plains with ERTS Paper Presented at the Third ERTS-1 Symposium, Washington, DC, NASA SP-351, 1 (A), 309-317.

Rubert, G. C., Roberti, D. R., Pereira, L. S., Quadros, F. L. F., Velho, H. F. C., Moraes, O. L. L. 2018. Evapotranspiration of the Brazilian Pampa Biome: Seasonality and Influential Factors. Water. 10, 1-18.

Simó, G., García-Santos, V., Jiménez, M., Martínez-Villagrasa, D., Picos, R., Caselles, V., \& Cuxart, J. 2016. Landsat and local land surface temperatures in a heterogeneous terrain compared to MODIs values. Remote Sensing, 8(10), 849.

Sobrino, J., Gomez, M., Jiménez-Muñoz, J., Olioso, A. 2007. Application of a simple algorithm to estimate daily evapotranspiration from NOAA-AVHRR images for the Iberian Peninsula. Remote Sensing of Environment, 110(2), 139-148.

Sobrino, J. A., Jiménez-Muñoz, J. C., Sòria, G., Romaguera, M., Guanter, L., Moreno, J., Plaza, A. and Martínez, P. 2008. Land Surface Emissivity Retrieval From Different VNIR and TIR Sensors. IEEE Trans. Geosci. Remote Sens. 46(2), 316327.

Tang, B. H., Shao, K., Li, Z. L., Wu, H., Nerry, F., \& Zhou, G. 2015. Estimation and validation of land surface temperatures from Chinese second-generation polar-orbit FY-3A VIRR data. Remote Sensing, 7(3), 3250-3273.

Vermote, E., Justice, C., Claverie, M., \& Franch, B. 2016. Preliminary analysis of the performance of the Landsat 8/OLI land surface reflectance product. Remote Sensing of Environment, 185, 46-56.

Vinukollu, R., Wood, E., Ferguson, C., Fisher, J. 2011. Global estimates of evapotranspiration for climate studies using multisensor remote sensing data: Evaluation of three process-based approaches. Remote Sensing of Environment, 115(3), 801-823.

Wang, F., Qin, Z., Song, C., Tu, L., Karnieli, A., Zhao. S. 2015 An Improved Mono-Window Algorithm fo r Land Surface Temperature Retrieval from Landsat 8 Thermal Infrared Sensor Data. Remote Sensing, 7(4), 4268-4289.

Yang, J., Wang, Y. 2011. Estimating evapotranspiration fraction by modeling two-dimensional space of NDVI/albedo and daynight land surface temperature difference: a comparative study. Advances in Water Resources, 34(4), 512-518.

Zheng, Y., Ren, H., Guo, J., Ghent, D., Tansey, K., Hu, X., Nie, J., Chen, S. 2019. Land Surface Temperature Retrieval from Sentinel3 a Sea and Land Surface Temperature Radiometer, Using a Split-Window Algorithm. Remote Sensing. 11(650).

Zoran, M. A., Savastru, R. S., Savastru, D. M., Dida, A. I., Ionescu, O. M. 2013. Impact of climate and anthropogenic changes on a periurban forest surface albedo derived from MODIS satellite data. Earth Resources and Environmental Remote Sensing/GIS Applications. Proc. of SPIE Vol. 8893, $88931 \mathrm{I}$ 